\title{
A fuzzy model for exploiting customer requirements
}

\author{
Zahra Javadirad $^{\mathrm{a}^{*}}$, Ali Akbarzadeh ${ }^{\mathrm{b}}$, Mehdi Khalili ${ }^{\mathrm{c}}$ and Delaram Shahrasari ${ }^{\mathrm{d}}$
}

${ }^{a}$ Department of Information Technology Management, Payame Noor University, Tehran, Iran

${ }^{b}$ Department of Business Management, Payame Noor University, Tehran, Iran

${ }^{c}$ Department of Computer and Informatics Engineering, Payame Noor University, Tehran, Iran

${ }^{d}$ Computer Engineering Software Group, Islamic Azad University, Tehran, Iran

CH R O N I C L E

Article history:

Received January 5, 2016

Received in revised format August 2, 2016

Accepted August 30, 2016

Available online

September 4, 2016

Keywords:

QFD

TOPSIS

Fuzzy

House of quality

\section{A B S T R A C T}

\begin{abstract}
Nowadays, Quality function deployment (QFD) is one of the total quality management tools, where customers' views and requirements are perceived and using various techniques improves the production requirements and operations. The QFD department, after identification and analysis of the competitors, takes customers' feedbacks to meet the customers' demands for the products compared with the competitors. In this study, a comprehensive model for assessing the importance of the customer requirements in the products or services for an organization is proposed. The proposed study uses linguistic variables, as a more comprehensive approach, to increase the precision of the expression evaluations. The importance of these requirements specifies the strengths and weaknesses of the organization in meeting the requirements relative to competitors. The results of these experiments show that the proposed method performs better than the other methods.
\end{abstract}

\section{Introduction}

Nowadays, quality function deployment (QFD) is one of total quality management tools, where the views and customers' requirements are perceived and using various tools, improves the production requirements and operations (Evans \& Lindsay, 2002). QFD was introduced by Akao in 1972 and Ford Motor company in the United State was the first firm to apply this technique (Cohen, 1995; Lin et al., 2008). QFD increases the ability of the organizations to make quick and accurate decisions and because of its great advantages for organizations it is increasingly developing (Chan \& Wu, 2005; Li et al., 2014). QFD approach consists of four interconnected matrix as follows: product planning (house of quality), product design, process planning and programming of process control. The main tool of QFD is the House of Quality matrix whose task is to translate the customer needs into the product design specifications. This matrix contains the requirements of customers and their importance, the product technical specifications and their importance, the relationship between customer requirements and 
technical specifications of product and the correlation between the technical specifications of the product (Fig. 1).

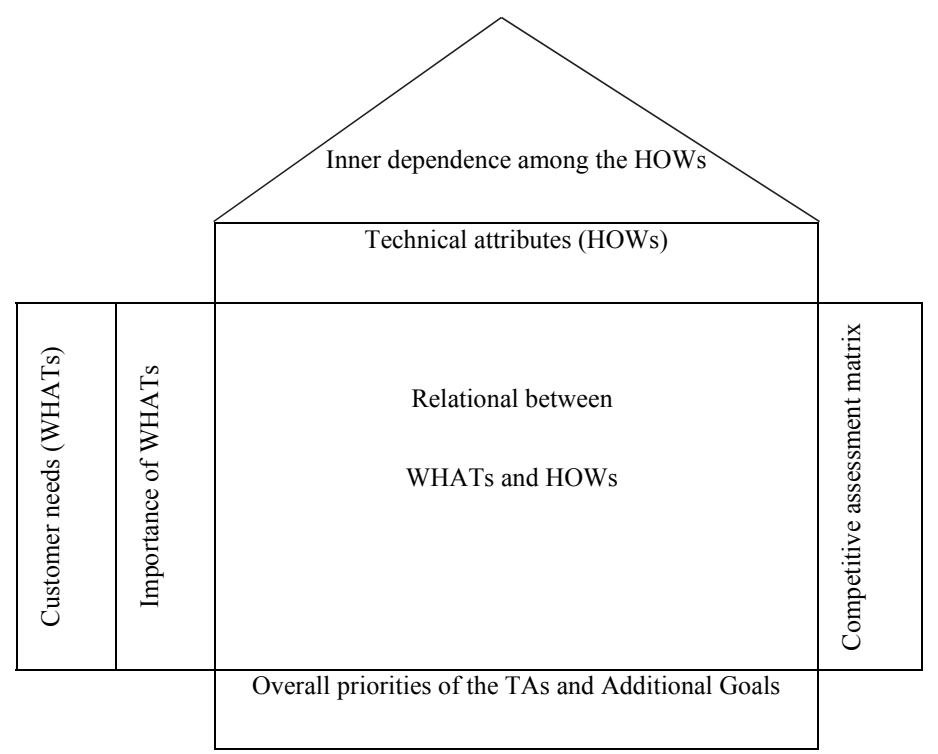

Fig. 1. The House of Quality matrix

Rating the importance of customer requirements is usually determined in the following four steps:

1- Identifying the customers and receiving their requirements,

2- Computing the raw weights of each customer's requirements,

3- Identifying the organization competitors and analyzing them,

4- Determining the relative weight of customer requirements and ranking their final.

The primary methods for identifying the customer's needs and receiving their requirements are to look for the actual locations of the exhausted products, interview, questionnaire, the comment cards installed on the product, tracking the customer complaints and focus groups. There have been significant amount of efforts devoted to determine customer requirements. The simplest method is to use a numerical scale like 1-5. Despite different groups of customers for a product and their different demands, it is possible to locate the relative importance of each group. One of the main problems for ranking the requirements is to use the chartering method. Because the expression of the customer aspects about the importance of their requirements usually are in linguistic forms, therefore the application of fuzzy linguistic variables is adapted which makes it easier to express opinions. Thus, the method of fuzzy pairwise comparisons made as a more efficient way (Kwong \& Bai, 2003). Of course, for each verbal variable there is a fuzzy number, which must be chosen according to the principles and experiences of the organization (Pawlak \& Skowron, 2007). Next, the QFD team, realize the customer requirements in the organization products and its competitors. In the final stage, according to the raw weight and competitive of the customer requirements, the relative weight of each customer requirements is achieved. Chosen (1995) defined a sales point as contains information characterizing the ability to sell product or services, according to how well each customer requirement is met. Usually a sales point indicates a unique selling position to separate one's own products from one's competitors. The firm may be proud of this selling position because competitors may not execute well in this customer requirement. Sales point can be grouped into three types: Strong, Moderate, and Poor, indicating the business opportunity from most to least, respectively. Every customer requirement can be grouped into the above three categories. Based on this categorization, a coefficient is devoted to each type of sales point. The most commonly used values are $1,1.25,1.5$, corresponding poor sales point, moderate sales point, and strong sales point, respectively. The final importance weight is computed multiplied by the relative importance rating to sales point value. The above sales point method is very straightforward, 
and there are many papers discussing it in QFD. However, this method is very subjective and may cause some problems. Then sales point method cannot help designers locate the customer requirement that can be strong sales point. It can only help to highlight the customer requirement that designers have decided to be a strong sales point.

In this paper, the relative weight of customer requirement combining the raw weight with competition weight is obtained and it is determined for each of opinions and customers' demands. Increasing the relative weight of each customer requirements is directly related to the increase in raw weight, if the customer demand is lower than other competitors, the relative weight of its demand will be increased. Using this approach, organizations may have a useful tool to identify the impact of the customer demands. The present article proposes a new model of decision-making group for ranking customer requirements.

\section{2- Literature review}

Lai et al. (2008) proposed a method based on fuzzy QFD, where the decision model determines the customer requirements in a competitive environment. In this model, the customers' insights about the demands of the products and competitors are received in the forms of linguistic variables. Then, using a mathematical function, competitive weight of each customer requirements is calculated and normalized as follows,

The relative weight $=$ raw weight + competitive coefficient $\times$ competitive weight

Here, raw weight of the customer requirements is computed by using paired comparisons. Competitive coefficient is determined according to the importance of the competitive environment, bigger, smaller or equal to one. Using this method helps us understand the weaknesses of the product, but in many cases, it offers irrational results. Based on this model, coefficients used in determining the relative weight of customer requirements are important, but the method is proposed for this purpose only.

\section{The proposed method for ranking competition requirements}

In the proposed method, according to the importance of customer requirements and an organization's current position of the product in the competitive environment, we prioritize customer requirements for product designers to improve the technical specifications. The priorities of redesign of the product is based on demands that the performance of the product is weaker compared to its competitors. In this paper, we assume the product of the desired organization is competitive in the current market and the product performance is assessed relative to competitors. The result of this paper ranks the customer requirements according to the importance of customer requirements and evaluates the performance of the product compared with other competitors. For the proposed method, all evaluations are intended to group decision making and in the fuzzy environment and to represent the fuzzy parameters, the trapezoidal fuzzy numbers are used (Dursun \& Karsak, 2013). Fig. 2 shows the general structure of the research model.

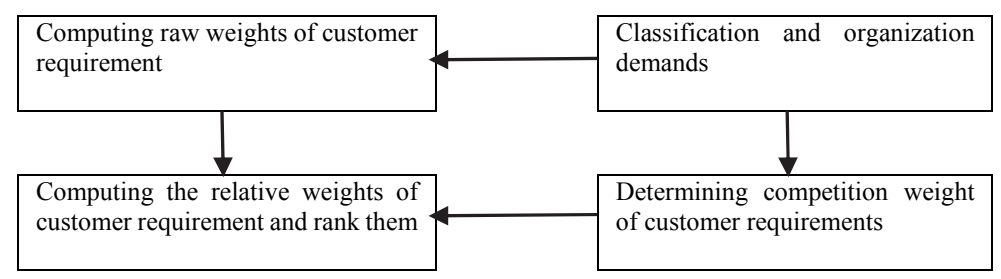

Fig. 2. The structure of provided model

\subsection{Classify and organize the customer demands}

The initial and critical step of the QFD process is the identification of what customers want and expect from a consumer product. In this step, customer's demands, expectations, and complaints are 
determined. Identified data contain current customer expectations that are critical to success and potential expectations that would excite customers are considered. Several methods can be applied to establish the customers' requirements, including: interview, self-completing questionnaires, focused group discussion, front-line staff feedback, customers' complaint and compliment database, telephone and internet connection. Feedback from our customers, expectations and actual demands of the product is received. To correct classify and organize the demands of customers, after reviewing and analyzing customers' requirements, we can use a tree diagram. Tree diagram is used to make sure that all the demands and requirements of the customer are identified and defined.

\subsection{Computing raw weight of the customers' requirements}

After identifying customers' requirements, to obtain the raw weight demands, using fuzzy TOPSIS (Behzadian et al, 2012) method is proposed. This method is a comprehensive decision-making procedure to choose an option with regard to the decision criteria ( $\mathrm{Li}, 2007)$. Therefore, after identifying customers' requirements, the amounts of importance of each demand is received from customers. The result of this feedback will be decision making matrices. Table 1 shows the matrix where $\mathrm{CR}_{\mathrm{m}}$ and $\mathrm{A}_{\mathrm{j}}$ display the demands and criteria, respectively.

\section{Table 1}

Assessment of customers' requirements

\begin{tabular}{cccc}
\hline & $A_{1}$ & $A_{2}$ &. \\
\hline$C_{1}$ & & & \\
\hline & & & \\
$\mathrm{CR}_{m}$ & & & \\
\hline
\end{tabular}

Customers use the linguistic variables to express the rating of the priority demands. As linguistic variables are comfortable and accurate for expressing decisions and consequently, the results of decisions will be obtained with higher accuracy. The fuzzy quantity for each linguistic variable is displayed in various forms (Lin et al., 2008). For the implementation of the proposed method, the trapezoidal fuzzy numbers are used to present variables. Table 2 shows an example of trapezoidal fuzzy parameters.

\section{Table 2}

The trapezoidal fuzzy quantities

\begin{tabular}{lccccc}
\hline The linguistic variable & Very low & Low & Middle & High & Very high \\
\hline Symbol & VL & L & M & H & VH \\
The fuzzy quantity & $(0,1,2,3)$ & $(2,3,4,5)$ & $(4,5,5,6)$ & $(5,6,7,8)$ & $(7,8,9,10)$ \\
\hline
\end{tabular}

After collecting the decision-making matrix, the final decision-making matrix must be calculated. Since all entryways are expressed into the linguistic variables, first linguistic variables must be converted to the corresponding fuzzy numbers. To obtain the final decision-making matrix, due to the rating of the importance of each customer, geometric mean of all matrixes must be calculated and consequently, the final decision-making matrix is obtained. If the number of customers are $L$ people and the rating of the importance of their aspects respectively is $\lambda_{1}, \ldots, \lambda_{L}$ then while the trapezoidal fuzzy numbers are used to represent the linguistic variables, for instance, element $K$ of matrix is computed as follows (Wang \& Chuu, 2004):

$$
\left(a_{f}^{k}, b_{f}^{k}, c_{f}^{k}, d_{f}^{k}\right)=\left(\frac{\sum_{i=1}^{L} \lambda_{i} a_{i}^{k}}{\sum_{i=1}^{L} \lambda_{i}}, \frac{\sum_{i=1}^{L} \lambda_{i} b_{i}^{k}}{\sum_{i=1}^{L} \lambda_{i}}, \frac{\sum_{i=1}^{L} \lambda_{i} c_{i}^{k}}{\sum_{i=1}^{L} \lambda_{i}} \frac{\sum_{i=1}^{L} \lambda_{i} d_{i}^{k}}{\sum_{i=1}^{L} \lambda_{i}}\right)
$$

where $\left(a_{f}^{k}, b_{f}^{k}, c_{f}^{k}, d_{f}^{k}\right)$ are the $k$ entryway of the final matrix and its corresponding entryway in $i$ matrix. This matrix is used for computing the raw weight of the customers' requirements. 


\subsection{Calculate the competition weight of customers' requirements}

At this stage, according to customer's evaluation of the performance of the product and its competitors in terms of achieving any of the demands, a method is presented for calculating the competitive weight of the customers' requirements. In this presented method, first the ratings the performance of the customers' demands in the product and its competitors have been polled. Then average matrix was determined and was incommensurable, finally due to the nearness of decision-making options (the product and its competitors) into the ideal solution, the competitive weight is calculated for each customers' requirements.

\subsubsection{Evaluate the performance of the organization product and its competitors}

The main purpose of this stage is to obtain the rates of the substantiation of customers' requirements in the organization product and its competitors from the customers' observatories. Initially customers with complementing the decision-making matrixes, shown in Table 3 , can evaluate the product and its competitors. In our decision-making criteria, customers' requirements is denoted by $\mathrm{CR}_{\mathrm{m}}$, and the alternatives matrix, organization (Org) and $n$ is its competitor $\left(\mathrm{R}_{\mathrm{n}}\right)$. After receiving the customers' comments which have been expressed in the form of linguistic variables, the fuzzy quantities (trapezoidal) is determined, finally geometric mean matrix using the Eq. (1) is computed. This matrix is inducted as the final decision-making matrix to calculate the relative weight of customers' requirements.

Table 3

Evaluate of the organization and competitors in the field of the substantiation of the demands

\begin{tabular}{llll}
\hline & $\mathrm{CR}_{1}$ & $\mathrm{CR}_{2}$ & $\mathrm{CR}_{\mathrm{m}}$ \\
\hline $\mathrm{Org}$ & & & \\
\hline $\mathrm{R}_{1}$ & & & \\
$\cdot$ & & & \\
$\mathrm{R}_{\mathrm{n}}$ & & & \\
\hline
\end{tabular}

\subsubsection{Calculate the closeness the decision options to the ideal solution}

After calculating the normalized decision matrix, since all decision criteria are positive, we used Eq. (2) to normalize the numbers of decision matrix ( $\mathrm{Li}, 2003)$.

$$
\widetilde{r}_{i j}=\left(\frac{a_{i j}}{d_{j}^{\max }}, \frac{b_{i j}}{d_{j}^{\max }}, \frac{c_{i j}}{d_{j}^{\max }}, \frac{d_{i j}}{d_{j}^{\max }}\right) .
$$

In the next stage, according to the measurement of the importance of each of the decision-making criteria which is determined, the harmonious incommensurable matrix is determined by product of the incommensurable matrix elements of the measurement of the importance of the criteria relative element. To determine the degree of the product performance in the realization of each customers' requirements, first, we assume the positive and negative ideal solutions for decision-making options are $(1,1,1,1)$ and $(0.0,0,0)$, respectively and the distance of the options from the positive ideal solution for each of the decision-making criteria $\left({ }^{d_{i j}^{+}}\right)$and the distance of the options from the negative ideal solution for each of the decision-making criteria $\left({ }^{d_{i j}^{-}}\right)$can be calculated. Then the relative proximity of the organizations' product and its competitors to the ideal solution for each customers' requirements is determined as follows,

$$
d_{j}^{-}=\sum_{i=2}^{l} \sqrt{\frac{\left(\sigma_{i j}\right)^{2}+2\left(\varsigma_{i j}\right)^{2}+2\left(\tau_{i j}\right)^{2}+\left(v_{i j}\right)^{2}}{6}},
$$




$$
\begin{aligned}
& d_{j}^{*}=\sum_{i=2}^{l} \sqrt{\frac{\left(1-\sigma_{i j}\right)^{2}+2\left(1-\varsigma_{i j}\right)^{2}+2\left(1-\tau_{i j}\right)^{2}+\left(1-v_{i j}\right)^{2}}{6}}, \\
& C_{j}=\frac{d_{j}^{-}}{\left(d_{j}^{-}+d_{j}^{+}\right)}, \quad j=1,2, \ldots, n
\end{aligned}
$$

\subsubsection{Determine the ratio improving and competitive weight of the customers' requirements}

To improve the product performance and to acquire the satisfaction of the customers, more attention should be given to the realization of the demands whose performance located on the irrelevancy conditions towards the other competitors' product. Then according to the obtained results in the previous stage, we should present a method for determining the competitive weight of the customers' requirements where it is magnified to the demands with the low throughput and consecutively the product designers complied the necessary proceedings for performance improvement. To determine the competitive weight of each of the customers' requirements, at the beginning towards improvement, Eq. (6) is used to calculate each of the customers' requirements.

$$
I R_{j}=C_{j}^{\text {Max }} / C_{J}^{\text {Org }}, \quad(j=1,2, \ldots, m)
$$

where $C_{j}^{\text {Max }}$ is the maximum amount of closeness of the $i$ th demands into all options and $C_{J}^{\text {Org }}$ is the relative closeness of the $j$ th demands of the organization product. Using this method, demands with the lowest of the throughput are compared with other competitors and the greatest amount of improvement is received. The lowest amount of improvement is attached to the demands of the maximum level of performance. To achieve improvement for customers' requirements, the competitive weight of them and for normalizing can be used as follows,

$$
W_{j t}^{\text {Norm }}=I R_{j} / \sum_{j=1}^{m} I R_{j}
$$

\subsection{Determine the relative weight of the customers' requirements}

Presently, the importance of the demands have been determined by customers, but to determine the relative weight each of the demands, we have to considere the functional status of the product in the competitive environment. In this study we use the raw weight and the resulting improvements for each of the customers' requirements, according to Eq. (8), the relative weight of the demands is determined. Also, similar to Eq. (7) we normalize the relative weight of the demands.

$$
W_{J c}=W_{j r} * I R_{j}, \quad(j=1,2, \ldots, m)
$$

Therefore, the relative weights of the demands according to the raw weight and the competitive conditions are determined.

\section{Implementation and results of the proposed model}

The proposed study of this paper can be used to determine the relative weights of customers' requirements for all products and services. In this study, for implementing the proposed method and to compare its results with another research, the product of highland bicycle is perused using the fuzzy TOPSIS method and according experts' opinions. This product has a different structure than conventional bikes. It is designed to be practical and convenient for customers in steep slopes and mountainous regions. After several investigations, the demand of customer is categorized in three main groups: the functional specifications, the dimensional requirements and the external characteristics. 
Demand of each group in the tree diagram is shown in Fig. 3 (Kwong \& Bai, 2002). As seen seven customers' requirements will be evaluated.

\subsection{Determine relative weight of customers' requirements}

First, customer evaluates the demands with regard to decision-making criteria using linguistic variables. Decision-making criteria for the assessment of demands which are determined by the QFD group include: quality, efficiency and beauty. After converting the linguistic variables to trapezoid fuzzy quantities and calculating the geometric mean, the decision-making matrix is determined. Then using fuzzy TOPSIS method, the raw weight of customers' requirements is calculated. In this example, we assume that the raw weights are achieved using the mentioned method and according to overviews of experts, shown in Table 4.

\section{Table 4}

The raw weight of customers' requirements

\begin{tabular}{lccccccc}
\hline Demand & $\mathrm{CR}_{1}$ & $\mathrm{CR}_{2}$ & $\mathrm{CR}_{3}$ & $\mathrm{CR}_{4}$ & $\mathrm{CR}_{5}$ & $\mathrm{CR}_{6}$ & $\mathrm{CR}_{7}$ \\
\hline Raw weight & 0.313 & 0.1128 & 0.313 & 0.0635 & 0.0898 & 0.0447 & 0.0633 \\
\hline
\end{tabular}

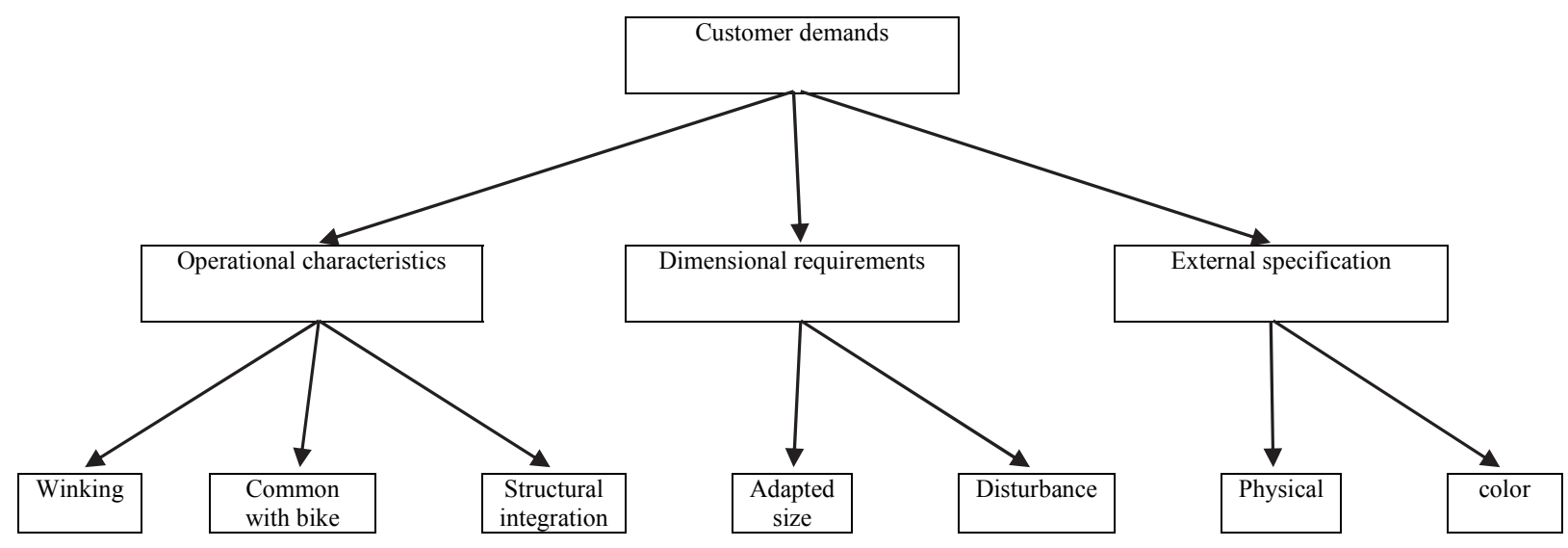

Fig. 3. The tree diagram of customers' requirements (Saaty \& Tran, 2007)

Table 5

The final matrix of performance evaluation of the organization product and competitors

\begin{tabular}{lccccccc}
\hline & $\mathrm{CR}_{1}$ & $\mathrm{CR}_{2}$ & $\mathrm{CR}_{3}$ & $\mathrm{CR}_{4}$ & $\mathrm{CR}_{5}$ & $\mathrm{CR}_{6}$ & $\mathrm{CR}_{7}$ \\
\hline Organization & $(3,4,5,7)$ & $(7,8,9,9.2)$ & $(5,6,7,7.2)$ & $(6,7.6,8,9)$ & $(3,4.5,5,6)$ & $(6,7.5,8,9)$ & $(5,6,7,7)$ \\
Competitor A & $(2,3,3,4)$ & $(3,4,4,5)$ & $(4,5,5,6)$ & $(3,4.5,5,6)$ & $(2,3.5,4,5)$ & $(4,5,5,6)$ & $(4,5,5.5,7)$ \\
Competitor B & $(2,3,4,4)$ & $(2,3.5,4,5)$ & $(5,6,7,7)$ & $(6,7,7,8)$ & $(4,5,5,6)$ & $(7,8,8,9)$ & $(6,7,7,8)$ \\
Competitor C & $(4,5,5,6)$ & $(5,6,6,7)$ & $(5,6,6,7)$ & $(3,4.6,5,6)$ & $(4,5,5.3,6)$ & $(4,5,6,6.2)$ & $(7,8,9,9.2)$ \\
Competitor D & $(7,8,9,9.2)$ & $(7,8,8,9)$ & $(4,5,6,6.2)$ & $(6,7,8,8)$ & $(4,5,6,6)$ & $(6,7,7,8)$ & $(7,8,8,9)$ \\
Competitor E & $(7,8,8,9)$ & $(6,7.5,8,9)$ & $(7,8,9,9.2)$ & $(7,8,8,9)$ & $(6,7.5,8,9)$ & $(7,8.4,9,10)$ & $(5,6.6,7,8)$ \\
\hline
\end{tabular}

In the next stage, customer evaluates the organization product and its competitors. There are five competitors for organization that produced similar products. These competitors are shown with the symbols A, B, C, D, E. After evaluation by customers and converting the linguistic variables into trapezoid fuzzy quantities and calculating the geometric mean, the final decision-making matrix is determined. In this example, the final decision-making matrix to assess the performance of the product and its competitors, according to the assumptions and opinions of the customers and experts in the Table 5 is presented. To calculate the proximity of product performance to the ideal solution, the 
decision-making matrix should be normalized using the Eq. (1). Then the distances of each alternative from positive ideal solution and negative ideal using the Eqs. (3-4) is calculated. Finally, the relative closeness to ideal solution is calculated using the Eq. (5). The rates of improvement and competitive weight of the customers' requirements, according to obtained highest closeness for each demands and for the organization product is calculated using the Eqs. (6-7).

Table 6

The normalized relative closeness of the demands and their competitive weight

\begin{tabular}{lccccccc}
\hline & $\mathrm{CR}_{1}$ & $\mathrm{CR}_{2}$ & $\mathrm{CR}_{3}$ & $\mathrm{CR}_{4}$ & $\mathrm{CR}_{5}$ & $\mathrm{CR}_{6}$ & $\mathrm{CR}_{7}$ \\
\hline Organization & 0.147 & 0.225 & 0.178 & 0.197 & 0.143 & 0.192 & 0.158 \\
competitor A & 0.055 & 0.086 & 0.126 & 0.110 & 0.088 & 0.106 & 0.125 \\
competitor B & 0.072 & 0.071 & 0.177 & 0.188 & 0.163 & 0.199 & 0.174 \\
competitor C & 0.167 & 0.177 & 0.167 & 0.111 & 0.168 & 0.121 & 0.189 \\
competitor D & 0.281 & 0.223 & 0.142 & 0.193 & 0.181 & 0.178 & 0.187 \\
competitor E & 0.278 & 0.218 & 0.211 & 0.201 & 0.257 & 0.205 & 0.167 \\
\hline Rate improving & 1.912 & 1 & 1.188 & 1.020 & 1.790 & 1.067 & 1.194 \\
Competitive weight & 0.209 & 0.109 & 0.130 & 0.111 & 0.195 & 0.116 & 0.130 \\
\hline
\end{tabular}

According to the obtained values for the raw weight and the improving rate of the demands, using the Eq. (8) the relative weights of customers' requirements in Table 8 are determined.

Table 7

The relative weight of the customers' requirements and ranking them

\begin{tabular}{lrrrrrrr}
\hline & $\mathrm{CR}_{1}$ & $\mathrm{CR}_{2}$ & $\mathrm{CR}_{3}$ & $\mathrm{CR}_{4}$ & $\mathrm{CR}_{5}$ & $\mathrm{CR}_{6}$ & $\mathrm{CR}_{7}$ \\
\hline Raw weight & 0.313 & 0.1128 & 0.313 & 0.0635 & 0.0898 & 0.0447 & 0.0633 \\
Rate improving & 1.9122 & 1 & 1.1880 & 1.0202 & 1.7896 & 1.0669 & 1.1938 \\
Relative weight & 0.5985 & 0.1128 & 0.3718 & 0.0648 & 0.1607 & 0.0477 & 0.0756 \\
Normalized relative weight & 0.4180 & 0.0788 & 0.2597 & 0.0452 & 0.1122 & 0.0333 & 0.0528 \\
\hline Ranking & 1 & 4 & 2 & 6 & 3 & 7 & 5 \\
\hline
\end{tabular}

\subsection{Compare the results}

After analyzing the results of the performed procedures with the proposed method, the comparison of the traditional method (raw weight), the competitive environment, the central distance and the new proposed method by considering the raw weight of criteria and the competitive weight is shown in the Table 8. It should be noted that if the criteria of compare results is the raw weight of the customer demands, the provided rankings by all methods, similar to the presented results are based on the traditional methods. Change in ranking of relative weight of the customers' requirements using other methods is shown in the Fig. 4.

\section{Table 8}

Ranking the customer demands to considering the criteria of raw weight, the competitive weight and the relative weight using the different methods

\begin{tabular}{|c|c|c|c|c|c|c|c|c|}
\hline Method & Criteria & $\mathrm{CR}_{1}$ & $\mathrm{CR}_{2}$ & $\mathrm{CR}_{3}$ & $\mathrm{CR}_{4}$ & $\mathrm{CR}_{5}$ & $\mathrm{CR}_{6}$ & $\mathrm{CR}_{7}$ \\
\hline \multirow{3}{*}{ Traditional (Lai et al., 2008) } & Raw weight & 1 & 3 & 1 & 5 & 4 & 7 & 6 \\
\hline & Competitive weight & - & - & - & - & - & - & - \\
\hline & Relative weight & 1 & 3 & 1 & 5 & 4 & 7 & 6 \\
\hline \multirow{3}{*}{ Competitive environment (Lai et al., 2008) } & Raw weight & 1 & 3 & 1 & 5 & 4 & 7 & 6 \\
\hline & Competitive weight & 3 & 7 & 5 & 6 & 1 & 4 & 2 \\
\hline & Relative weight & 1 & 5 & 3 & 7 & 2 & 6 & 4 \\
\hline \multirow{3}{*}{ Central distance (Mehdizadeh, 2010) } & Raw weight & 1 & 3 & 1 & 5 & 4 & 7 & 6 \\
\hline & Competitive weight & 4 & 7 & 1 & 6 & 3 & 5 & 2 \\
\hline & Relative weight & 2 & 7 & 1 & 6 & 3 & 5 & 4 \\
\hline \multirow{3}{*}{ Proposed method } & Raw weight & 1 & 3 & 1 & 5 & 4 & 7 & 6 \\
\hline & Competitive weight & 1 & 7 & 4 & 6 & 2 & 5 & 3 \\
\hline & Relative weight & 1 & 4 & 2 & 6 & 3 & 7 & 5 \\
\hline
\end{tabular}


By comparing the results of different methods, it is determined that the ranking of the customers' requirements using the proposed method is very different than the other methods, the reasons for the differences are as follows: the traditional method depends on the raw weight determined by the customers while the performance of the product in the competitive environment is not taken into account. In the competitive environment, the sum of the raw weight and competitive weight is determined by considering the importance of the coefficients and the raw weights of demands are determined using fuzzy analytical hierarchy process (Armacost et al., 1994; Saaty \& Tran, 2007). In the central distance method, the priority is based on improving the demands performance which contained the same performance in the organization products and its competitors from the customers' perspective. For the proposed, the raw weights of demands are calculated using fuzzy TOPSIS method which is an adaption method for determining the importance of the options and the competitive weight based on attainment to location of the highest competitors. Finally, to determine the ratio of recovery, the final weight combining raw and competitive weight is determined.

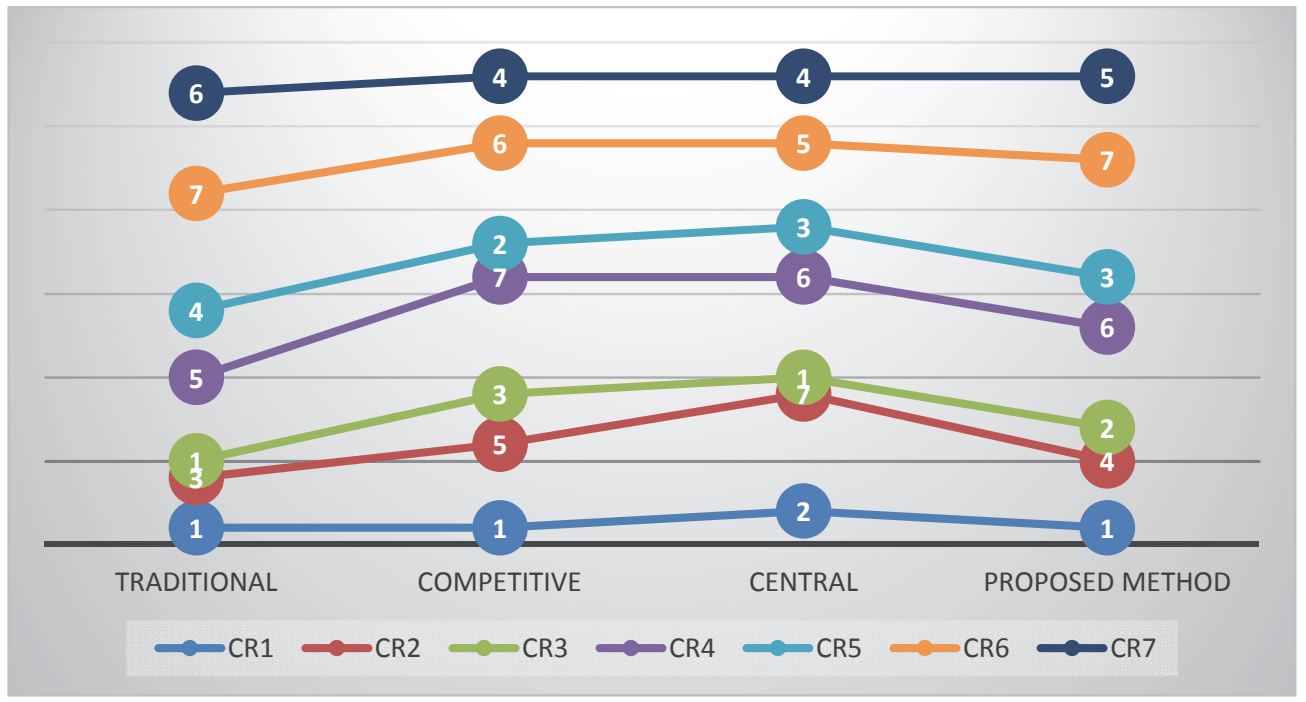

Fig. 4. Ranking the relative weight of demands using the different methods.

\section{Conclusion}

To raise the level of customer satisfaction from the product of an organization, after evaluating the importance of customers' requirements, it is necessary to evaluate the product performance and to improve the product performance. Due to the limitations of organizations for deep improvement, prioritizing the improvement of the product performance is required to fulfill each customers' requirements. By raising the level of the product performance, the level of the customer satisfaction is increased. Therefore, improving the position of the products compared with the best competitor is one of the requirements to obtain customer satisfaction and market position. In addition, the technical characteristics which leads to poor performance in the competitive market, in priority must be improved. In this study, a new decision-making method to determine the importance of customers' requirements according to mentioned gleanings has been proposed. In this method, the final prioritizing of the customers' requirements has been determined by an integration of the two approaches: the determined importance for each of the customers' requirements and the evaluation of demands performance in the organization product and its competitors in this decision-making method. This capability makes accurate assessments made by decision makers and with the existence of the correct input, the final results of decision problems are closer to reality.

Comparison the proposed method with other methods shows that the final ranking the customer demands using the proposed method has presented the logical results. The ease of the use of the proposed method and its application is one of the advantages of the proposed method for all 
organizations in this study. The final results of the proposed method could be the basis for determining the ranking the product technical requirements that in the next stage the matrix of the quality house (technical information) is used.

\section{References}

Armacost, R. L., Componation, P. J., Mullens, M. A., \& Swart, W. W. (1994). An AHP framework for prioritizing customer requirements in QFD: an industrialized housing application. IIE transactions, 26(4), 72-79.

Behzadian, M., Otaghsara, S. K., Yazdani, M., \& Ignatius, J. (2012). A state-of the-art survey of TOPSIS applications. Expert Systems with Applications, 39(17), 13051-13069.

Chan, L. K., \& Wu, M. L. (2005). A systematic approach to quality function deployment with a full illustrative example. Omega, 33(2), 119-139.

Cohen, L. (1995). Quality function deployment: how to make QFD work for you. Prentice Hall.

Dursun, M., \& Karsak, E. E. (2013). A QFD-based fuzzy MCDM approach for supplier selection. Applied Mathematical Modelling, 37(8), 5864-5875.

Evans, J. R., \& Lindsay, W. M. (2002). The management and control of quality (Vol. 5, pp. 115-128). Cincinnati, OH: South-Western.

Kwong, C. K., \& Bai, H. (2002). A fuzzy AHP approach to the determination of importance weights of customer requirements in quality function deployment. Journal of Intelligent Manufacturing, 13(5), 367-377.

Kwong, C. K., \& Bai, H. (2003). Determining the importance weights for the customer requirements in QFD using a fuzzy AHP with an extent analysis approach. IIE Transactions, 35(7), 619-626.

Lai, X., Xie, M., Tan, K. C., \& Yang, B. (2008). Ranking of customer requirements in a competitive environment. Computers \& Industrial Engineering, 54(2), 202-214.

Li, D. F. (2003). Fuzzy multiobjective many-person decision makings and games. National Defense Industry Press, Beijing, 138-158.

Li, D. F. (2007). Compromise ratio method for fuzzy multi-attribute group decision making. Applied Soft Computing, 7(3), 807-817.

Li, M., Jin, L., \& Wang, J. (2014). A new MCDM method combining QFD with TOPSIS for knowledge management system selection from the user's perspective in intuitionistic fuzzy environment. Applied Soft Computing, 21, 28-37.

Lin, M. C., Wang, C. C., Chen, M. S., \& Chang, C. A. (2008). Using AHP and TOPSIS approaches in customer-driven product design process. Computers in Industry, 59(1), 17-31.

Mehdizadeh, E. (2010). Ranking of customer requirements using the fuzzy centroid-based method. International Journal of Quality \& Reliability Management, 27(2), 201-216.

Pawlak, Z., \& Skowron, A. (2007). Rudiments of rough sets. Information sciences, 177(1), 3-27.

Saaty, T. L., \& Tran, L. T. (2007). On the invalidity of fuzzifying numerical judgments in the Analytic Hierarchy Process. Mathematical and Computer Modelling, 46(7), 962-975.

Wang, R. C., \& Chuu, S. J. (2004). Group decision-making using a fuzzy linguistic approach for evaluating the flexibility in a manufacturing system.European Journal of Operational Research, 154(3), 563-572.

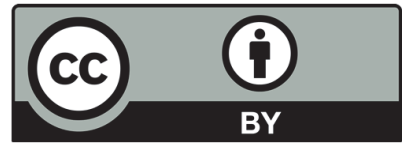

(C) 2016 by the authors; licensee Growing Science, Canada. This is an open access article distributed under the terms and conditions of the Creative Commons Attribution (CC-BY) license (http://creativecommons.org/licenses/by/4.0/). 